\title{
Impact of COVID-19 on Malaria Elimination: Juxtaposing Indoor Residual Spraying and Mobile Phones in Buhera Rural District, Zimbabwe
}

Elliot Mbunge ( $\nabla$ mbungeelliot@gmail.com )

University of Swaziland https://orcid.org/0000-0003-4504-6697

Richard Millham

Durban University of Technology - ML Sultan Campus: Durban University of Technology

Maureen Nokuthula Sibiya

Durban University of Technology - ML Sultan Campus: Durban University of Technology

\section{Sam Takavarasha}

Women's University in Africa

\section{Research}

Keywords: COVID-19, Malaria Elimination, Indoor Residual, Spraying and Mobile, Buhera Rural District, Zimbabwe

Posted Date: February 15th, 2021

DOI: https://doi.org/10.21203/rs.3.rs-173130/v2

License: (9) This work is licensed under a Creative Commons Attribution 4.0 International License. Read Full License 


\section{Abstract}

\section{Background}

Globally, malaria remains one of the leading health problems decimating population in Africa with an estimated 228 million cases of malaria and 405000 deaths occurred worldwide in 2018. In Zimbabwe, like other sub-Saharan countries, is fighting both elusive malaria and COVID-19 that continues to overwhelm the already overburdened healthcare system. Zimbabwean rural healthcare centres including Buhera district experience dire impact of malaria and COVID-19 pandemic. Therefore, the study presents the impact of COVID-19 on malaria control measures and reflects on indoor residual spraying (IRS) activities pre and post the outbreak of COVID-19 while introspecting milestones and challenges encountered when executing IRS activities; and opportunities to integrate mobile technologies into malaria elimination.

\section{Methods}

A retrospective study of malaria cases and IRS reports was carried out. Malaria cases per each health centre from 20152020 were collected from DHIS in Buhera rural district.

\section{Results}

The study shows that the overall IRS acceptance rate in 2015, 2016, 2017, 2018 and 2019 was 100\%, 58.5\%, 66.6\%, 52.8\% and $83.3 \%$, respectively. The absolute rooms sprayed in 2017 are $2.55 \%$ above those sprayed in 2016 but are $8.46 \%$ below those sprayed in 2015. The coverage failed to reach impact levels in most of the wards due but not lack of resources, limited to inadequate community sensitization, and competing programmes which were running concurrently with IRS. Also, the study revealed that malaria confirmed cases increased tremendously in 2020 as compared to the previous years, particularly from 2015-2019 because of delayed IRS coverage, COVID-19 restrictions, heavy rains, differed and inconsistent social and behaviour change communication, lack of community engagement, delayed procurement of equipment and lack of funding among others.

\section{Conclusions}

The study revealed that moving from malaria prevention to elimination is possible in low malaria incidence areas in Buhera rural district. However, new challenges including cyclones and COVID-19, disrupts of movements of medical equipment, delayed IRS activities, social and behaviour change communication and IEC campaigns and mandatory national lockdowns. It is therefore imperative to integrate mobile phones into malaria control strategies during COVID-19 pandemic to strengthen awareness campaigns while maintaining COVID-19 regulations.

\section{Background}

An estimated 229 million cases of malaria and 409000 deaths which occurred worldwide means that malaria remains one of the leading killer diseases particularly in Africa which experienced 215 million of the estimated malaria cases and 384 000 malaria deaths in 2019[1]. However, there has been substantial progress in malaria control globally owing to intensified efforts including malaria control and elimination strategies, policies, funding, and cross-border malaria initiatives which are in line with the sustainable development goal (SDG) 3 target 3.3. These malaria initiatives, policies and strategies accelerate and sustain malaria control and elimination at national, regional and global levels. Although the African region contributed more malaria cases, there has been significant progress because most countries in sub-Saharan Africa have adopted aggressive strategies to mitigate malaria pandemic.

In sub-Saharan Africa countries including Zimbabwe, malaria dominates public health problems ahead of other diseases such as tuberculosis (TB), human immunodeficiency virus infection and acquired immune deficiency syndrome (HIV/AIDS) [2]. Zimbabwe is one of the member states of Elimination 8 , a malaria strategic policy which aims to eliminate malaria in 
Southern African Development Community (SADC), through cross-border initiatives and coordinated and synchronized malaria control programmes[3]. In Zimbabwe, the number of reported malaria cases fluctuates between approximately 300,000 and 500,000 cases per year, with a notable sustained downward trend in recent years[4]. Such achievement has led to the reorientation of focus from malaria control to elimination[5] in Matabeleland North, Midlands and Mashonaland West Provinces and the Government promoted the implementation of malaria pre-elimination operations in some districts[3]. However, despite enthusiasm and reorientation of focus from malaria control to elimination in low transmission areas, there is limited evidence that malaria burden has decreased significantly. For instance, approximately 310,000 malaria cases were reported in 2019 countrywide, equivalent to an incidence rate of 22 cases per 1,000 population[6]. This represented a 19\% increase in the number of cases reported in 2018 (approximately 260,000), and the number of malaria deaths also rose from 236 in 2018 to 266 in 2019[6].

Most epidemic-prone districts are located within Manicaland and Mashonaland East. Out of the sixty rural districts in Zimbabwe, fifty-one are high burdened and malarious with varying transmission intensity, and malaria outbreaks predominantly occurring in the eastern and northern border districts[7,8]. This happened despite the implementation of malaria prevention and activities such as vector control, intermittent preventative therapy in pregnancy (ITPp), case management, social and behaviour change communication (SBCC) among others intervention strategies. Vector control management includes the implementation and distribution of insecticide-treated bed nets (ITNs) or long-lasting treated nets (LLINs) and IRS and utilization of artemisinin-based combination therapy (ACT) in malarial areas experiencing continuous malaria transmission.

In Manicaland province, which is the focal point of the study, malaria is unstable and seasonal, closely influenced by environmental factors such as land surface temperature, rainfall and precipitation patterns[9,10]. Also, $[11,12]$ reported that increased malaria transmission is attributed to limited funding, drug resistance insecticide resistance, inadequate epidemic preparedness and response, continuous dwindling of resources, and technical and operational challenges. Therefore, the study analyses IRS activities from 2015-2020 for malaria control while introspecting milestones and challenges encountered and opportunities to integrate mobile technologies into malaria control strategies in vulnerable rural communities so that it can complement indoor residual spraying.

\section{The rise of digital technologies in Zimbabwe's healthcare system}

The introduction of e-health strategy 2012 - 2017 was a paradigm shift towards the adoption of mobile health, telemedicine systems, electronic health record (EHR) in Zimbabwe's health system to expedite health data access, sharing, remote, monitoring of patient and synchronization of medical activities. The health system was once amongst the best in subSaharan Africa and later severely suffered in the period 2000 to 2009 due to several factors including hyperinflation, political instability[13], policy inconsistencies, lack of funding, lack of infrastructure, and the outbreak of preventable and treatable conditions such as Human Immunodeficiency Virus (HIV) infection and acquired immune deficiency syndrome, TB, acute respiratory infections, hypertension and malaria[14]. This calls for robust, effective and provision of health information systems, disease prevention, monitoring and control strategies and collaborative efforts with different stakeholders as part of a strategic response to malaria and other communicable diseases, which requires the use of mobile technology to complement existing techniques. Subsequently, Zimbabwe's health system adopted the monthly reporting system, Tally system, rapid disease notification system (RDNS) and Weekly Disease Surveillance System (WDSS) to disseminate health information. However, these systems were not completely fully functional in some areas[2]. For example, [15] highlighted that sending health data from district health facility to the national level using Tally system would take up to a month, thereby, affecting timely surveillance, monitoring and reporting. Besides the challenge of timeliness, there was no real-time integration of health data amongst the Tally system, RDNS and WDSS; and overburdened healthcare professionals with parallel-reporting hence making it difficult to integrate and consolidate reports. To counter the weaknesses and challenges of the previous health information dissemination systems, Zimbabwe through the Ministry of Health and Child Care installed national health information Systems (NHIS) in 2010 to capture, and manage surveillance 
and integration of health data at district, provincial and national level. The NHIS was successfully implemented through the district health information system, which was rolled out to sixty-three districts, eight provincial offices and four city health information offices in 2013. The transition from paper-based reporting system to national health information systems strengthen and integrate health information system activities in all provinces and districts. The introduction of national health information systems, district health information systems version 2 (DHIS2), malaria control and elimination strategies was enhanced by training of workforce and funding from local and international stakeholders which resulted in achieving significant progress in 2014. This was evidenced by the complete, faster, more accurate, more reliable and more efficient system for surveillance of malaria, tuberculosis, human immunodeficiency virus infection and acquired immune deficiency syndrome (HIV/AIDS)[12].

\section{Information, education and communication (IEC), community sensitization and Disease Surveillance}

Since the advent of national health information system in Zimbabwe, mobile phones have played a significant role in improving health service delivery through enhanced reporting and surveillance of malaria and other pandemics. For instance, the Ministry of Health and Child Care through Zimbabwe Health Information and Support Project (ZimHISP) introduced mobile-phone-based Weekly Disease Surveillance System (WDSS) in more than seventy-five per cent of health facilities countrywide. WDSS was developed using open-source software called Frontline SMS, to enhance health facilities to transmit data using short messaging services (SMS) text messaging to a central server that automatically transfers the data to DHIS2[16]. The WDSS is also used to relay health information such as malaria indoor residual spraying, human immunodeficiency virus infection viral load and other health information related to male circumcision. The WDSS specifically used by healthcare professionals for disease and event reporting. Also, Econet Wireless group developed EcoHealth app, which provides paid mobile phone health advisory service for each text message. EcoHealth was launched after the success of Ecocash, mobile money platform that sends and receive money. EcoHealth allows users to track important information related to health delivery at a cost by offering health tips and sending reminders to subscribers. This reflects that there is little use of the responsive technology for diseases monitoring, awareness, reporting and surveillance. Also, [17] highlighted that the future of Zimbabwe's health system relies on the adoption of emerging technologies to effectively monitoring, diagnosing, sharing of information, reporting, creating awareness and surveillance of pandemics including malaria, while maximizing the use of available resources.

The advent of COVID-19 which has drawn a lot of attention from health services providers has potential to spur malaria cases, hence continued sensitizing vulnerable communities through information, education and communication (IEC) programmes are critical pre-prevention activities in rural districts to increase acceptance and enhance uptake of malaria interventions. Pre-COVID-19, rural health centres in Buhera have been disseminating information through community gatherings, posters, brochures, billboards, and pamphlets among others, which is no longer feasible during the pandemic. It is therefore important to use innovative information dissemination methods such as mobile phones, radio, and television to reinforce social behaviour change, enhance community engagement and creating malaria and COVID-19 awareness. Mobile phone messages, radio and television awareness campaigns should incorporate information on malaria and COVID-19 symptoms, appropriate prevention measures, and emergence numbers of the nearest health centres.

\section{Methods}

\section{Study area and population}

Zimbabwe experiences seasonal variations of malaria transmission, Manicaland province being amongst highly malaria burdened provinces in Zimbabwe[18]. Manicaland province is made up of seven districts; Buhera, Chimanimani, Chipinge, Makoni, Mutare, Mutasa and Nyanga. Based on cumulative from 2005-2014, Buhera district was the leading pack in malaria incidences [19]. The country started using indoor residual household spraying, particularly using benzene hexachloride (BHC), dichloro-diphenyl-trichloro-ethane (DDT) in the 1940s[20], and later switched to pyrethroids and organophosphate[21], while, long-lasting insecticidal nets were first introduced in 2010[22]. Buhera is prone to public health 
problems including malaria, cholera, anthrax and rabies episodes. There are thirty-four (34) health centres in the district comprising of three hospitals and thirty-one clinics, with Birchenough Bridge hospital and Murambinda mission hospital being the referral centres. Buhera district has an estimated population of 245,878 , with four constituencies and a total of thirty-three administrative wards (IRS being implemented in twelve wards)[23]. Buhera rural district adopted IRS and LLINs (although bed nets were last distributed in 2014), together with case management as vector control management interventions for reducing malaria transmission. In Buhera rural district, LLINs are regularly distributed through mass campaigns, prioritizing people living in high malaria prevalence wards in the district. Also, IRS coverage is done according to previous malaria prevalence in the wards.

\section{Data source}

The study analyzed malaria cases from 2015-2020 and indoor residual spraying (IRS) reports from 2015- 2019. Malaria cases per each health facility and IRS reports were obtained from Buhera district health office, which is under the arm of the Ministry of Health and Child Care under the ethical clearance number MRCZ/A/205.

\section{Ethical approval}

Intermittent residual spraying reports were obtained under the ethical clearance number MRCZ/A/205, which was obtained from the Medical Research Council of Zimbabwe (MRCZ) operating under the MoHCC.

\section{Results}

The IRS activities for the year 2020 was delayed, not yet done at the time of writing due to COVID-19 pandemic, hence the unavailability of 2020 IRS report.

\section{IRS implementation schedule}

In Buhera, IRS is implemented in twelve wards with high malaria perennial and high malaria sporadic as shown in Figure 1 camp wards. The reports show that the IRS is implemented in the form of teams and camps that are divided according to malaria prevalence in the wards. The number of teams and camps varies with respect to the implementation strategy. In some cases, the camps and teams were grouped into three camps of three teams each. The designated camps were Birchenough, Muzokomba and Mudawose as shown in Figure 1. Each camp was to cover four wards based at the same campsite. Three teams usually camp at Muzokomba covering wards $24,25,26$, and 27 . Another set of three teams usually camp at Betera covering wards 18, 20 and part of ward 23 then move to Masasa to cover ward 22 and part of ward 23, and four teams camp at Birchenough Bridge (BB) covering wards 28, 29, 30 and 33. The movement of IRS teams in their respective wards is shown in Figure 1. Malaria season is usually from November to April in Zimbabwe but in most cases, IRS is done during malaria peak time, that is, between January and April[21].

\section{Five-year intermittent residual spraying (IRS) comparative ward coverage from 2015 to 2019}

Table 1 shows IRS coverage from 2015 to 2019, with the total number of targeted rooms and sprayed rooms and their respective wards. IRS acceptance rate is the rate at which indoor residual spraying activities are accepted in the targeted rooms of the targeted area, while callbacks refer to the return of IRS activities for the second or more times, to improve coverage in the affected areas[24]. The IRS acceptance rate per ward and or per year was calculated by dividing the total number of targeted rooms by the total number of sprayed rooms and multiplies the result by 100 to get the percentage. Therefore, the overall IRS acceptance rate in 2015, 2016, 2017, 2018 and 2019 was 100\%, 58.5\%, 66.6\%, 52.8\% and 83.3\%, respectively. The acceptance rate of sprayed rooms in ward 18 for the year 2015, 2016, 2017, 2018 and 2019 was $100 \%$, $66.9 \%, 62.9 \%, 0 \%$ and $92.3 \%$ respectively, while, ward 20 has acceptance rate of $100 \%$ in $2015,66.9 \%$ in $2016,75.1 \%$ in 2017 and $14.4 \%$ in 2019 . Ward 22 has acceptance rate of $100 \%$ in $2015,69.3 \%$ in $2016,66.5 \%$ in $2017,72.2 \%$ in 2018 and $88 \%$ in 2019. In 2017, there was not much difference between the targeted rooms and the rooms sprayed, with notable difference 
only in ward 33 which was influenced by accelerated growth. Acceptance was generally low across all the wards, except for ward 26 which had an acceptance of $84.27 \%$. The lowest acceptance rate was in ward 23 which registered $56.72 \%$. The absolute rooms sprayed in 2017 are 2.55\% above those sprayed in 2016 but are 8.46\% below those sprayed in 2015 . Acceptance rate dropped in the two concurrent years, dropping from $71.72 \%$ in 2015 to $69.21 \%$ and $67.53 \%$ in 2016 and 2017 respectively. Callbacks were instituted in the wards with low coverage, wards 18, 20, 23, and ward 30, however, insignificant rooms were sprayed during callbacks as the community continued to resist despite prior engagement with the community leaders. In 2018, acceptance was generally low across all the wards, except for ward 26 which had an acceptance of $84.27 \%$. The lowest acceptance rate was in ward 23 which registered $56.72 \%$. In 2019 , the overall sprayed rooms coverage was $83.3 \%$ against target and population protected was $95.5 \%$. The coverage failed to reach impact levels in most of the wards due, but not limited, to inadequate community sensitization, as well as a competing programme which was running concurrently with IRS. Ward 33 and 30 are problematic wards since the community is preoccupied with their irrigation activities, hence refusal rate and the locked rate was very high.

\section{Sprayed rooms}

Figure 2 shows the distribution of sprayed rooms from 2015-2019. Ward 22 had the highest IRS coverage in terms of rooms sprayed from 2015-2019. This high distribution might be attributed to sensitization awareness, promotion and marketing of the programme, while ward 30 recorded slightly low sprayed rooms in 2015,2016, 2017,2018 and 2019. Ward 30 and 33 are problematic areas with very high refusal affected by competing farming and marketing activities. Ward 26 had a sudden decline in acceptance, compared to the previous years when the ward was one of the best performing wards with coverage above impact levels.

\section{Comparative analysis of wards IRS coverage and achievements at wards level}

The overall acceptance rate stood at $67.42 \%$ and the overall coverage achieved was $66.58 \%$ as shown in Table 2 . There was not much difference between the targeted rooms and the rooms sprayed, with notable difference only in ward 33 which was influenced by accelerated growth. Acceptance was generally low across all the wards, except for ward 26 which had an acceptance of $84.27 \%$. The lowest acceptance rate was in ward 23 which registered $56.72 \%$. The absolute rooms sprayed in 2017 are $2.55 \%$ above those sprayed in 2016 but are $8.46 \%$ below those sprayed in 2015. Acceptance rate dropped in the 2 concurrent years, dropping from $71.72 \%$ in 2015 to $69.21 \%$ and $67.53 \%$ in 2016 and 2017 respectively. Callbacks were instituted in the wards with low coverage, wards 18,20,23, and ward 30, however, insignificant rooms were sprayed during callbacks as the community continued to resist despite prior engagement with the community leaders.

In 2018, the acceptance was generally low across all the wards, with the highest coverage achieved in ward 26 with $75 \%$ as shown in Table 3. The lowest coverage was achieved in ward 30 which had 51\%. Wards 18 and 28 were not sprayed as fuel shortage affected operations at Birchenough and Mudawose campsites. Ward 20 had only $21 \%$ of the rooms reached with only $14 \%$ being sprayed. The overall coverage for the targeted wards stood at $53 \%$ but the coverage for the sprayed wards excluding those not sprayed was $66 \%$. Acceptance was greatly affected by poor warning and poor deployment, due to shortage of fuel. It was also affected by poor promotion and marketing of the programme and the new chemical.

In 2019 , the overall sprayed rooms coverage was $83.3 \%$ against target and population protected was $95.5 \%$. The coverage failed to reach impact levels in most of the wards because of limited inadequate community sensitization, as well as the competing programme which was running concurrently with IRS. Ward 33 and 30 are problematic wards since the community is preoccupied with their irrigation activities, hence refusal rate and the locked rate was very high.

There was a steady decline in coverage from 2016 to 2018, which can be attributed to several challenges including poor marketing of the programme, high refusal, and poor resource inflow especially operational resources among others. In the 2019 season, the coverage improved in some wards culminating to a better coverage than three preceding seasons though 
not enough to reach impact levels. Vigorous marketing and awareness of the programme at village/ward level are required to improve the uptake of the programme; however, poor resource inflows affect the implementation of the programme.

\section{Distribution of malaria cases from 2015-2020}

Malaria data from satellite health facilities are entered into district health information system 2(DHIS) on weekly basis. Satellite health centres report aggregated monthly malaria confirmed cases (tested positive) and suspected cases (tested by rapid diagnostic test or blood slide) using T5 forms[25]. Once data is entered, it then becomes accessible nationally through NHIS. Satellite health facilities report malaria cases using WhatsApp, SMS, phone call and frontline app. Once the malaria data is entered, it becomes accessible electronically at the district level, provincial level up to national level. This follows the malaria outbreak detection and response surveillance system reporting structure shown in Figure 3.

Following malaria outbreak detection and response surveillance system reporting structure shown in Figure 3, malaria cases collected from DHIS from 33 rural health facilities in Buhera rural district from 2015-2020 are shown in Table 6.

Low malaria confirmed deaths and cases were recorded in 2018 which shows a clear reduction in malaria burden, as shown in Table 6, which brought hope and prospects to policymakers, funders, healthcare professionals and the community to move towards malaria elimination[3]. However, there was a sharp increase of confirmed malaria cases in 2019 because of new challenges including changes in vector behaviour [26], high refusal of IRS activities, resistance to insecticides and antimalarial medicines[27], invasion of new areas by vectors, vectors in various combination of sympatry, changes in vector proportions, outdoor malaria transmission, climate change[9], abuse of LLINs, lack of meticulousness of spray operators and lack of digital tools to sensitize affected communities about malaria as well as IRS activities[8]. Also, the outbreak of COVID-19 pandemic stalls the progress and gains achieved in the previous years as depicted in Table 6, although 2020 results alone may not be sufficient to warrant a trend. The confirmed malaria cases increased from 1376 cases in 2019 to 2981 cases in 2020. This is attributed by several factors including imposed COVID-19 stringent restrictions, delayed IRS activities, postponement of recruitment and training of IRS teams and disruption of movements of medical equipment $[28,29]$.

\section{Malaria hotspots and distribution in Buhera rural district}

After collecting confirmed malaria cases from 2015-2020, we mapped malaria hotspots using QGIS 3.10.5 software. Cumulative confirmed malaria cases per each health facility were mapped into their respective wards in Buhera district. Health facilities were grouped into several categories such as malaria-free, low malaria sporadic, high malaria sporadic and high malaria perennial as shown in Figure 4. These categories are based on malaria prevalence rate on each health facility. Figure 4'shows that high malaria perennial wards are ward 28 (Chapanduka) and ward 33 (Birchenough Bridge). Ward 30, $29,25,21,23,20$ and 23 were identified as high malaria sporadic wards and low malaria perennial wards, respectively. This means that indoor residual spraying activities and resources should be intensively done in high malaria perennial wards and high malaria sporadic wards. However, there are some low malaria sporadic wards with low transmission and reported cases as well as malaria-free wards which are close to malaria elimination as shown in Figure 4.

\section{Social and behaviour change communication (SBCC) in changing malaria landscape in Buhera rural district}

SBCC is one of the malaria control strategies in Zimbabwe aimed at increasing utilization of correct malaria prevention and control measures. After programme inception, data indicated high refusal rates and locked rooms especially in wards $28,23,24,18$ and 33 as shown in Table 2. The correlation between high refusals and locked rooms suggested that the locked rooms could have been just smart refusals linked to fear of the impact of chemical spraying, ignorance, uncertainty, perceived side effects of the insecticide[30], odour, and conspiracy theory about the chemical affecting fertility and people exposing their poor quality household possessions. After SBCC campaigns communities anticipated chemical change, though it was based on resistance management. 
The new strategy to involve and engage the local leadership, chiefs, headman, village heads and the community might reduce resistance. The phenomenon primarily focused on problem identification, analysis and possible solutions in a participatory manner to enhance community engagement in order to reduce high IRS refusals. This was employed in all areas targeted for callbacks and all areas to be covered by the IRS. Principally communities agreed to work together and to provide guides in most instances. SBCC activities in rural health centres are carried out by nurses and environmental health technicians through scheduled and ad-hoc health education sessions to patients and vulnerable populace[31]. In some instances, malaria posters and pamphlets written in local languages are used to relay malaria messages in hard-to-reach areas. In urban areas, walls at local shops and branded public transport vehicles also facilitate SBCC[31]. However, the effectiveness of these SBCC malaria interventions is not yet known or document especially in high malaria risk zones. Therefore, introducing mobile technology to complement existing strategies is seen as a positive move to enhance malaria control.

\section{Challenges of malaria elimination strategies in Buhera district}

Despite the remarkable progress in combating malaria in Buhera district, the district is faced by multiple challenges. These include the shortage of resources, low or non-response to field challenges including high refusal of IRS, competing programme and activities such as farming and food distributions demanding same resources (i.e human and time) also affected acceptance, inconsistent SBCC messaging threatening the success of the programme and poor programme promotion, awareness and marketing strategies among others. Buhera district's malaria elimination progress is also threatened by other challenges affecting the NMCP as explained by [21]These challenges include changes in vector behaviour, resistance to insecticides and anti-malarial medicines, invasion of new areas by vectors, vectors in various combination of sympatry, changes in vector proportions, outdoor malaria transmission, climate change, lack of meticulousness of spray operators, lack and inconsistency of funding, lack of political-will[12], low utilization and distribution of treated nets in the district, outdoor transmission, lack of community engagement, lack of information and commitment, lack of mapping malaria models in low-transmission settings[32]. These challenges are likely to slow down malaria elimination in Buhera district.

\section{Opportunities for integrating mobile phones in malaria prevention and elimination in Buhera rural district}

Since the country is prepared to introduce Integrated Vector Management (IVM) as part of the vector management and elimination, there is a need to adopt and utilize mobile phones to strengthen BSCC and malaria information, education, and communication irrespective of locality. Also, [8] stated that there was a notable decline in exposure to malaria messages despite relatively high ownership of radios, televisions and mobile phones among the households sampled in the malaria indicator survey conducted in 2016. This affects the knowledge of people living in high malaria incidences as it correlates to lack of information such as signs and symptoms of malaria as well as perceived dangers of malaria. In addition, COVID-19 presents a challenge to disseminate information while maintaining physical distancing especially in rural communities where inequality in access to information and the digital divide is common. Hence, the need for best alternative solutions to information, education, and communication such as low cost-effective mobile technologies including mobile phones to disseminate malaria information. Studies by[33-36] indicated that integration of mobile phones in malaria prevention and elimination strengthens information, education and communication as well as improve case detection and management of malaria. The high mobile phone penetration of over 90 per cent makes mobile phones a readily available means of communication even in Zimbabwe`s resource-constrained areas[37]. Malaria vector prevention could focus on disseminating malaria information and knowledge of the symptoms and danger signs of malaria as well as the importance of indoor residual spraying[8] because of their pervasiveness and ubiquity. For instance, [38]suggested that mobile phones connected to the existing technologies such as cloud computing, geographical information systems, could be utilized to map malaria hotspots, migration patterns of infected people, malaria detection and reporting. Also, [39]identified vertebrate blood meals in the malaria vector (Anopheles arabiensis) using mid-infrared spectroscopy, while[40] applied GIS and machine learning classifiers to understand spatial variations of malaria that are linked to remotely sensed data in Vietnam. 
Also, [41] also applied the convolutional neural network (CNN) image analysis for malaria diagnosis, and detect malaria from microscopic images. However, the integration of these existing technologies and mobile phones to tackle malaria may be independent; and could be utilized for various purposes such as predicting malaria incidences[9], malaria diagnosis[41], detecting malaria, identification of malaria-infected cells, malaria screening, predicting insecticide resistance[42], predicting of mosquito species, mapping malaria hotspots and associated climatic factors[10], malaria cell image classification[43] among others. This shows that there are so many unprecedented opportunities to embrace emerging technologies in malaria prevention and control strategies in Zimbabwe.

\section{How COVID-19 slows down malaria control and prevention measures in Zimbabwe?}

COVID-19 pandemic continues disrupting international, regional, national, provincial and districts malaria control programmes complicating malaria surveillance and monitoring activities as well as slowing down planning and resource mobilization processes, especially in low-income tropical malaria-endemic countries [44]. Considering that the malaria burden is highest in low-income tropical countries with little capacity to fund malaria control and eradication programs, the fight against malaria in these regions is likely to be hampered[45]. Access to healthcare has generally been limited, while malaria interventions, such as seasonal malaria chemotherapy and distribution of insecticide-treated bed nets, have been suspended due to lockdowns[46]. Likewise, the repurposing of anti-malarials for treatment of COVID-19 shared symptoms and the shift in focus from the production of malaria rapid diagnostic tests (RDTs) to COVID-19 RDTs is a cause for concern in malaria-endemic regions[47]. The use of chloroquine and its derivatives in COVID-19 treatment is likely to facilitate the rebound of chloroquine-resistant malaria parasites. This will hinder the possible use of chloroquine and its derivatives in the fight against malaria in the future and thus further dampen the prospects of malaria elimination from Africa.

Recently, WHO emphasized that malaria control programmes in malaria-endemic countries should be done while protecting the vulnerable communities and healthcare professionals against COVID-19 pandemic[48]. Despite WHO' recommendations, sub-Saharan African countries including Ghana, Côte d'Ivoire and Comoros deferred the insecticide-treated bed nets and indoor residual spraying campaigns amid COVID-19 pandemic[49]. However, the current COVID-19 pandemic continues disrupting malaria prevention and control programme, movements of medical equipment and recursive national lockdowns with stringent access to health care could lead to additional loss of life[50]. Also, WHO warned that up to 769000 people could die of malaria this year in sub-Saharan Africa, more than double the number of deaths in 2018, if the focus on COVID19 leads to a disruption of interventions for malaria[51]. Also, [49,52] state that the association between malaria and COVID19 pandemic is devastating in malaria-endemic countries with myriad health problems such as fragile healthcare system, scant healthcare professionals, poor healthcare facilities and infrastructure and limited financial resources. This threatens progress made towards malaria elimination in malaria-endemic countries in the past years[53,54]. Such progress was largely successfully because of the effective implementation of malaria control and prevention measures, including the distribution of long-lasting insecticide-treated bed nets, indoor residual spraying, and antimalarial treatments. In the context of the ongoing pandemic, implementing and sustaining these malaria control and prevention measures require innovative measures to save both vulnerable communities and healthcare professionals especially in vulnerable rural resourceconstrained areas.

Zimbabwe with no exception especially the vulnerable rural communities, mosquito vector control largely depends on indoor residual spraying and also the mass distribution of long-lasting insecticide-treated nets[20]. Indoor residual spraying is the most dominant vector control intervention that has been implemented by the Ministry of Health and Child Care to reduce malaria in malaria-endemic districts. However, indoor residual spraying poses the highest risk of exposure to COVID-19 because IRS teams frequently and physically engage with the community when recruiting participants, training, meeting authorities, executing household visits, and in some instances conduct contaminated objects and surfaces[44]. Also, the imposed by COVID-19 measures restrict movements of people both rural and urban areas making it difficult to recruit IRS operators, training, conduct meetings and gather the community. COVID-19 restrictions also cause delays in the procurement of resources and planning for seasonal IRS. Typical delays caused by COVID-19 include increased time taken 
to deliver personal protective equipment and IRS chemicals, and other consumables[55], postponement of recruitment and training of IRS teams due to disruption in the movements of medical equipment, closed borders and recursive national lockdowns. Owing to COVID-19 restrictions especially movements of people[56], the recruitment and training of IRS teams require a new different approach and innovative means. Coupled with a lack of adequate personal protective equipment and the scarcity of knowledge on the possible interaction between malaria and COVID-19 both in terms of presentations and shared symptoms, this has left many frontline health workers with fears and anxieties[28]. It is therefore imperative for both health workers including IRS teams and community to receive training and information pertaining to COVID-19 and IRS activities that impose risks and how to mitigate them effectively. This increases the cost of additional resources and training required to fight both the pandemic and elusive malaria, without redirecting resources.

Notably, IRS coverage is done based on classifying areas into different malaria risk zones in a stratified manner, prioritizing malaria hotspots areas followed by lower-risk areas. This should be done timeously usually from early November to April to spray mosquito breeding sites. However, due to the postponement of the recruitment and training process, IRS activities were delayed leading to malaria outbreak. For instance, as of April 2020, few months after the pronouncement of COVID-19 national lockdown, Zimbabwe recorded a cumulative 135,585 malaria cases and 131 deaths, mostly from malarious provinces such as Manicaland, Masvingo and Mashonaland East[57]. This calls for the need for robust and resilient innovative measures to expedite IRS activities and equip communities with knowledge of malaria and COVID-19 prevention measures.

\section{Potential integration of IRS and mobile phones in malaria control to enhance IEC in Buhera rural district}

Moving from malaria prevention to complete elimination is a daunting task that requires collaborative efforts from regulators, institutions, funders, researchers, community among others to integrate and coordinate malaria prevention and control strategies. To achieve complete malaria elimination, the inclusion of emerging technologies and computational models in the future national malaria communication strategy is inevitable. This means re-establishment of sound e-health strategy in collaboration with the Ministry of ICT, Postal and Courier Services. The following suggestions can be incorporated in the future malaria information, education and communication programmes:

- Integration of mobile phones to create malaria awareness, community engagement, communicate IRS chemical changes and LLINs to avoid high refusal when executing IRS activities

- Re-establishment of e-health strategy which might lead to e-health policy in Zimbabwe.

- Mobile phones enhance real-time reporting, monitoring and surveillance of malaria cases because of their pervasiveness and ubiquity.

- Resource mobilization through funding and research collaborations with local and international institutions

- Development of multi-sectoral (Ministry of ICT, Postal and Courier Services, Ministry of Health and Child Care and other stakeholders) framework and guidelines for the adoption and use of ICTs in the health sector to facilitate the adoption of e-health for easy monitoring, diagnosis and surveillance of malaria and other preventable and treatable pandemics.

- Creating malaria awareness and promote IRS and LLINs, strengthening information, education, and communication on malaria through low-cost and feasible information dissemination platforms.

\section{Recommendations for malaria control at ward level are as follows}

- IRS is field-based and in the event of challenges should seek field solutions

- Conduct client satisfaction survey and feedback meetings to note areas of improvement and identify areas which were missed during the IRS and or LLINs programme

- Community dialogue especially pre and post IRS meetings in areas with high refusal rates to come up with a plan to address issues surrounding refusals

Page 10/22 
- Baseline data verification is needed.

\section{Conclusion}

Moving from malaria prevention to elimination is possible in low malaria incidence areas in Zimbabwe. However, in some areas, the goal of malaria elimination remains bleak because of challenges including continuous dwindling resources for vector control, changes in vector behaviour, the emergence of resistance to medicines and insecticides, climate change, environmental degradation, diversity in ecology, breeding habitats, and community habits, changes in vector behaviour, resistance to insecticides and anti-malarial medicines, invasion of new areas by vectors, vectors in various combination of sympatry, changes in vector proportions, outdoor malaria transmission, climate change, lack of meticulousness of spray operators, lack and inconsistency of funding, political conflicts, low utilization and distribution of treated nets in the district, outdoor transmission, lack of community engagement, lack of information and commitment, lack of mapping malaria models in low-transmission settings.

After synthesis of the IRS reports from 2015 to 2019, it emerged that, it is imperative to integrate mobile phones and IRS as part of the malaria control strategies. Disseminating malaria information through mobile phones could strengthen social and behaviour change communication and also IEC campaigns by facilitating delivering vector control messages especially in resource-constrained areas.

The acquisition of mobile phones in most of Zimbabwe's rural areas is increasing, making mobile phones the most feasible communication gadget for people in resource-constrained areas[17]. Also, many of Zimbabwe population (over 67\%) lives in rural areas[58] and heavily depends on mobile phones for communication and making payments using mobile money platforms such as EcoCash, One-Money, MyCash and Tele-Cash because of cash shortages[59]. Owing to this proliferation, mobile phones especially short messaging service (SMS) could be utilized to promote and market IRS programme and campaigns in malaria hotspots area and high-risk population in Buhera rural district. Applying mobile phones in malaria prevention and control strategies can enhance case detection, monitoring, surveillance as well as strengthening information, education, and communication activities and campaigns while maintaining COVID-19 regulations[60]. However, with technology, it is common that functionalities of gadgets are underutilized (people know how to receive and make calls only)implying owners require more education on how to maximize utilization of their gadgets.

\section{Abbreviations}

\%: Per cent

ICT: Information and Communication Technologies

IEC: Information, Education and Communication

IRS: Indoor residual spraying

IoT: Internet of Things

IVM: Integrated Vector Management

ITN: Insecticide-treated mosquito net

LLIN: Long-lasting insecticidal net

MoHCC: Ministry of Health and Child Care

MRCZ: Medical Research Council of Zimbabwe

Page $11 / 22$ 
NMCP: National Malaria Control Programme

SBCC: Social and Behaviour Change Communication

WHO: World Health Organization

\section{Declarations}

\section{Acknowledgements}

We would like to appreciate the Medical Research Council of Zimbabwe and Buhera Health Office and the Ministry of Health and Child Care as well as Durban University of Technology for allowing us to carry out this study. Many thanks go to healthcare professionals working at Buhera Health Office.

\section{Availability of data and materials}

Data used in this study are available from the corresponding author on reasonable request.

\section{Ethics approval and consent to participate}

This study received ethical clearance from the Medical Research Council of Zimbabwe (MRCZ) and Buhera district health office under the ethical clearance number MRCZ/A/205.

\section{Consent for publication}

The authors take full responsibility for publication.

\section{Competing interests}

The authors declare that they have no competing interests.

\section{Funding}

Funding information is not applicable.

\section{Authors' contributions}

EM, RM, MNS and ST conceived the research. EM and ST participated in the ethical clearance process and fieldwork. EM, RM, MNS and ST contributed to draft the manuscript, editing reviewing and revision of manuscript. All authors read and approved the final manuscript.

\section{Corresponding author}

All correspondences should be forwarded to Elliot Mbunge.

\section{References}

1. WHO. World malaria report 2020: 20 years of global progress and challenges [Internet]. 2020 [cited 2021 Jan 20]. Available from: https://www.wipo.int/amc/en/

2. Hannah H, Brezak A, Hu A, Chiwanda S, Simckes M, Revere D, et al. Field-based evaluation of malaria outbreak detection and response in Mudzi and Goromonzi districts, Zimbabwe - 2017. Glob Public Health [Internet]. Routledge; 2019 [cited 2021 Jan 20];14:1898-910. Available from:

https://www.tandfonline.com/doi/full/10.1080/17441692.2019.1642367 
3. Sande S, Zimba M, Chinwada P, Masendu HT, Mberikunshe J, Makuwaza A. A review of new challenges and prospects for malaria elimination in Mutare and Mutasa Districts, Zimbabwe. Malar. J. 2016.

4. President U, Initiative M. FY 2019 Zimbabwe Abbreviated Malaria Operational Plan. 2019.

5. Mundagowa PT, Chimberengwa PT. Malaria outbreak investigation in a rural area south of Zimbabwe: A case-control study. Malar J. 2020;

6. President's Malaria Initiative | Zimbabwe | CDC Global Health [Internet]. [cited 2021 Feb 5]. Available from: https://www.cdc.gov/globalhealth/countries/zimbabwe/annual-report/pmi.html

7. THE NATIONAL HEALTH STRATEGY EQUITY AND QUALITY IN HEALTH: LEAVING NO ONE BEHIND for Zimbabwe.

8. Dube B, Mberikunashe J, Dhliwayo P, Tangwena A, Shambira G, Chimusoro A, et al. How far is the journey before malaria is knocked out malaria in Zimbabwe: Results of the malaria indicator survey 2016. Malar J. 2019;

9. Gunda R, Chimbari MJ, Shamu S, Sartorius B, Mukaratirwa S. Malaria incidence trends and their association with climatic variables in rural Gwanda, Zimbabwe, 2005-2015. Malar. J. 2017.

10. Ebi KL, Hartman J, Chan N, McConnell J, Schlesinger M, Weyant J. Climate suitability for stable malaria transmission in Zimbabwe under different climate change scenarios. Clim Change. 2005;

11. Kanyangarara M, Mamini E, Mharakurwa S, Munyati S, Gwanzura L, Kobayashi T, et al. Individual- and household-level risk factors associated with Malaria in Mutasa District, Zimbabwe: A serial cross-sectional study. Am J Trop Med Hyg. 2016;

12. Chung AM, Case P, Gosling J, Gosling R, Madinga M, Chikodzore R, et al. Scaling up malaria elimination management and leadership: A pilot in three provinces in Zimbabwe, 2016-2018. Malar J. 2020;

13. Furusa SS, Coleman A. Factors influencing e-health implementation by medical doctors in public hospitals in Zimbabwe. SA J Inf Manag. 2018;

14. Kidia KK. The future of health in Zimbabwe. Glob Health Action. 2018;

15. Khumalo NB, Mnjama N. The effect of eHealth information systems on health information management in hospitals in Bulawayo, Zimbabwe. Int J Healthc Inf Syst Informatics. 2019;

16. Chidawanyika H, Nyika P, Katiyo J, Sox A, Chokuda T, Peter K, et al. Success in Revitalizing Weekly Disease Surveillance System in Zimbabwe Using Cell-phone Mediated Data Transmission, 2009-2013. Online J Public Health Inform. 2014;

17. Zhou M, Herselman M, Coleman A. USSD technology a low cost asset in complementing public health workers' work processes. Lect Notes Comput Sci (including Subser Lect Notes Artif Intell Lect Notes Bioinformatics). 2015.

18. Kureya T, Ndaimani A, Mhlanga M. Malaria outbreak investigation in Chipinge, Zimbabwe: A case-control study. Iran J Parasitol. 2017;

19. Mutsigiri F, Mafaune PT, Mungati M, Shambira G, Bangure D, Juru T, et al. Malaria morbidity and mortality trends in Manicaland province, Zimbabwe, 2005-2014. Pan Afr Med J. 2017;

20. Taylor P, Mutambu SL. A review of the malaria situation in zimbabwe with special reference to the period 1972-1981. Trans. R. Soc. Trop. Med. Hyg. 1986.

21. Sande S, Zimba M, Mberikunashe J, Tangwena A, Chimusoro A. Progress towards malaria elimination in Zimbabwe with special reference to the period 2003-2015. Malar J. 2017;

22. Tapera O. Determinants of long-lasting insecticidal net ownership and utilization in malaria transmission regions: Evidence from Zimbabwe Demographic and Health Surveys. Malar J. 2019;

23. ZimStat. Zimbabwe Population Census 2012. Popul Census Off. 2012;

24. Usaid, Pmi. PMI VectorLink Zimbabwe End of Spray Report [Internet]. Available from: www.abtassociates.com

25. Hannah HA, Brezak A, Hu A, Chiwanda S, Simckes MS, Revere D, et al. Field-based Evaluation of Malaria Outbreak Detection \& Response, Mudzi and Goromonzi. Online J Public Health Inform. 2019; 
26. Munhenga G, Masendu HT, Brooke BD, Hunt RH, Koekemoer LK. Pyrethroid resistance in the major malaria vector Anopheles arabiensis from Gwave, a malaria-endemic area in Zimbabwe. Malar J. 2008;

27. Masendu HT, Hunt RH, Koekemoer LL, Brooke BD, Govere J, Coetzee M. Spatial and temporal distributions and insecticide susceptibility of malaria vectors in Zimbabwe. African Entomol. 2005.

28. Kusotera T, Nhengu TG. Coronavirus-19 and malaria: The great mimics. African J Prim Heal Care Fam Med. 2020;

29. Dzobo M, Chitungo I, Dzinamarira T. COVID-19: a perspective for lifting lockdown in Zimbabwe. Pan Afr. Med. J. 2020.

30. Kaufman MR, Rweyemamu D, Koenker H, MacHa J. My children and i will no longer suffer from malaria: A qualitative study of the acceptance and rejection of indoor residual spraying to prevent malaria in Tanzania. Malar J. 2012;

31. Muchena G, Dube B, Chikodzore R, Pasipamire J, Murugasampillay S, Mberikunashe J. A review of progress towards sub-national malaria elimination in Matabeleland South Province, Zimbabwe (2011-2015): A qualitative study. Malar. J. 2018.

32. Manyangadze T, Chimbari MJ, Macherera M, Mukaratirwa S. Micro-spatial distribution of malaria cases and control strategies at ward level in Gwanda district, Matabeleland South, Zimbabwe. Malar J. 2017;

33. Buckee CO, Wesolowski A, Eagle NN, Hansen E, Snow RW. Mobile phones and malaria: Modeling human and parasite travel. Travel Med. Infect. Dis. 2013.

34. Prue CS, Shannon KL, Khyang J, Edwards LJ, Ahmed S, Ram M, et al. Mobile phones improve case detection and management of malaria in rural Bangladesh. Malar J. 2013;

35. Quan V, Hulth A, Kok G, Blumberg L. Timelier notification and action with mobile phones-towards malaria elimination in South Africa. Malar J. 2014;

36. Githinji S, Kigen S, Memusi D, Nyandigisi A, Wamari A, Muturi A, et al. Using mobile phone text messaging for malaria surveillance in rural Kenya. Malar J. 2014;

37. UNICEF Zimbabwe and Econet launch the Internet of Good Things | UNICEF Zimbabwe [Internet]. [cited 2021 Jan 23 ]. Available from: https://www.unicef.org/zimbabwe/stories/unicef-zimbabwe-and-econet-launch-internet-good-things

38. Scherr TF, Gupta S, Wright DW, Haselton FR. Mobile phone imaging and cloud-based analysis for standardized malaria detection and reporting. Sci Rep. 2016;

39. Mwanga EP, Mapua SA, Siria DJ, Ngowo HS, Nangacha F, Mgando J, et al. Using mid-infrared spectroscopy and supervised machine-learning to identify vertebrate blood meals in the malaria vector, Anopheles arabiensis. Malar J. 2019;

40. Bui QT, Nguyen QH, Pham VM, Pham MH, Tran AT. Understanding spatial variations of malaria in Vietnam using remotely sensed data integrated into GIS and machine learning classifiers. Geocarto Int. 2019;

41. Liang Z, Powell A, Ersoy I, Poostchi M, Silamut K, Palaniappan K, et al. CNN-based image analysis for malaria diagnosis. Proc - 2016 IEEE Int Conf Bioinforma Biomed BIBM 2016. 2017.

42. Weetman D, Donnelly MJ. Evolution of insecticide resistance diagnostics in malaria vectors. Trans R Soc Trop Med Hyg. 2015;

43. Sai Bharadwaj Reddy A, Sujitha Juliet D. Transfer learning with RESNET-50 for malaria cell-image classification. Proc 2019 IEEE Int Conf Commun Signal Process ICCSP 2019. 2019.

44. Brooke BD, Raman J, Frean J, Rundle K, Maartens F, Misiani E, et al. Implementing malaria control in South Africa, Eswatini and southern Mozambique during the COVID-19 pandemic. South African Med J. 2020;

45. Haakenstad A, Harle AC, Tsakalos G, Micah AE, Tao T, Anjomshoa M, et al. Tracking spending on malaria by source in 106 countries, 2000-16: an economic modelling study. Lancet Infect Dis. 2019;

46. Nghochuzie NN, Olwal CO, Udoakang AJ, Amenga-Etego LNK, Amambua-Ngwa A. Pausing the Fight Against Malaria to Combat the COVID-19 Pandemic in Africa: Is the Future of Malaria Bleak? Front Microbiol. 2020;

47. Principi N, Esposito S. Chloroquine or hydroxychloroquine for prophylaxis of COVID-19. Lancet Infect. Dis. 2020. 
48. Diptyanusa A, Zablon KN. Addressing budget reduction and reallocation on health-related resources during COVID-19 pandemic in malaria-endemic countries. Malar J. 2020;

49. Guerra CA, Tresor Donfack O, Motobe Vaz L, Mba Nlang JA, Nze Nchama LO, Mba Eyono JN, et al. Malaria vector control in sub-Saharan Africa in the time of COVID-19: no room for complacency. BMJ Glob Heal. 2020;

50. Mbunge E, Akinnuwesi B, Fashoto SG, Metfula AS, Mashwama P. A critical review of emerging technologies for tackling COVID-19 pandemic. Hum. Behav. Emerg. Technol. 2020.

51. WHO urges countries to move quickly to save lives from malaria in sub-Saharan Africa [Internet]. [cited 2021 Jan 19]. Available from: https://www.who.int/news/item/23-04-2020-who-urges-countries-to-move-quickly-to-save-lives-frommalaria-in-sub-saharan-africa

52. Di Gennaro F, Marotta C, Locantore P, Pizzol D, Putoto G. Malaria and covid-19: Common and different findings. Trop. Med. Infect. Dis. 2020.

53. Ranaweera P, Wickremasinghe R, Mendis K. Preventing the re-establishment of malaria in Sri Lanka amidst the COVID19 pandemic. Malar J. 2020;

54. Rogerson SJ, Beeson JG, Laman M, Poespoprodjo JR, William T, Simpson JA, et al. Identifying and combating the impacts of COVID-19 on malaria. BMC Med. 2020.

55. Rahi M, Das P, Sharma A. COVID-19 mitigation steps provide a blueprint for malaria control and elimination. Am. J. Trop. Med. Hyg. 2020.

56. Mbunge E. Integrating emerging technologies into COVID-19 contact tracing: Opportunities, challenges and pitfalls. Diabetes Metab Syndr Clin Res Rev. 2020;

57. Zimbabwe faces malaria outbreak as it locks down to counter coronavirus | Global development | The Guardian [Internet]. [cited 2021 Jan 19]. Available from: https://www.theguardian.com/globaldevelopment/2020/apr/21/zimbabwe-faces-malaria-outbreak-as-it-locks-down-to-counter-coronavirus

58. Thior I, Rowley E, Mavhu W, Kruse-Levy N, Messner L, Falconer-Stout ZJ, et al. Urban-rural disparity in sociodemographic characteristics and sexual behaviors of HIVpositive adolescent girls and young women and their perspectives on their male sexual partners: A cross-sectional study in Zimbabwe. PLoS One. 2020;

59. Marumbwa J. An Analysis of the Factors Influencing Consumers' Adoption of Mobile Money Transfer Services (MMTs) in Masvingo Urban, Zimbabwe. Br J Econ Manag Trade. 2013;

60. Mbunge E. Effects of COVID-19 in South African health system and society: An explanatory study. Diabetes Metab Syndr Clin Res Rev. 2020;

\section{Tables}

Table 1: Intermittent residual spraying coverage from 2015-2019 


\begin{tabular}{|c|c|c|c|c|c|c|c|c|c|c|}
\hline & \multicolumn{5}{|c|}{ Targeted rooms } & \multicolumn{5}{|c|}{ Sprayed rooms } \\
\hline & $\begin{array}{l}\text { Year } \\
2015\end{array}$ & $\begin{array}{l}\text { Year } \\
2016\end{array}$ & $\begin{array}{l}\text { Year } \\
2017\end{array}$ & \begin{tabular}{|l|} 
Year \\
2018
\end{tabular} & \begin{tabular}{|l|} 
Year \\
2019
\end{tabular} & $\begin{array}{l}\text { Year } \\
2015\end{array}$ & $\begin{array}{l}\text { Year } \\
2016\end{array}$ & $\begin{array}{l}\text { Year } \\
2017\end{array}$ & \begin{tabular}{|l|} 
Year \\
2018
\end{tabular} & $\begin{array}{l}\text { Year } \\
2019\end{array}$ \\
\hline $\begin{array}{l}\text { Ward } \\
18\end{array}$ & 4239 & 5531 & 5007 & 4230 & 4230 & 4239 & 3689 & 3151 & 0 & 3905 \\
\hline $\begin{array}{l}\text { Ward } \\
20\end{array}$ & 5487 & 6196 & 5850 & 5706 & 5706 & 5487 & 4146 & 4395 & 822 & 4771 \\
\hline $\begin{array}{l}\text { Ward } \\
22\end{array}$ & 7025 & 7801 & 8197 & 7901 & 7901 & 7025 & 5407 & 5456 & 5702 & 6953 \\
\hline $\begin{array}{l}\text { Ward } \\
23\end{array}$ & 4854 & 7425 & 6850 & 7411 & 7411 & 4854 & 3871 & 4121 & 5295 & 6847 \\
\hline $\begin{array}{l}\text { Ward } \\
24\end{array}$ & 5376 & 6635 & 6851 & 7101 & 7101 & 5376 & 5232 & 4469 & 5122 & 6121 \\
\hline $\begin{array}{l}\text { Ward } \\
25\end{array}$ & 6430 & 6969 & 6004 & 7493 & 7493 & 6430 & 4464 & 4380 & 4445 & 6253 \\
\hline $\begin{array}{l}\text { Ward } \\
26\end{array}$ & 3687 & 4374 & 7620 & 6505 & 6505 & 3687 & 2366 & 5386 & 4878 & 4821 \\
\hline $\begin{array}{l}\text { Ward } \\
27\end{array}$ & 4633 & 5563 & 5563 & 4733 & 4733 & 4633 & 2927 & 2906 & 2884 & 3973 \\
\hline $\begin{array}{l}\text { Ward } \\
28\end{array}$ & 5965 & 5808 & 5965 & 6244 & 6244 & 5965 & 2758 & 3587 & 0 & 6422 \\
\hline $\begin{array}{l}\text { Ward } \\
29\end{array}$ & 4733 & 7321 & 7321 & 6326 & 6326 & 4733 & 2966 & 4358 & 4387 & 4199 \\
\hline $\begin{array}{l}\text { Ward } \\
30\end{array}$ & 2921 & 3727 & 3727 & 3641 & 3641 & 2921 & 1778 & 2557 & 1858 & 2729 \\
\hline $\begin{array}{l}\text { Ward } \\
33\end{array}$ & 5286 & 6187 & 6136 & 8312 & 8312 & 5286 & 3428 & 5233 & 4557 & 5993 \\
\hline Total & 60636 & 73537 & 75091 & 75603 & 75603 & 60636 & 43032 & 49999 & 39950 & 62987 \\
\hline
\end{tabular}


Table 22017 Wards IRS coverage and achievements

\begin{tabular}{|c|c|c|c|c|c|c|c|c|c|c|c|}
\hline WARD & $\begin{array}{r}\text { TARGET } \\
\text { ROOMS } \\
\end{array}$ & \begin{tabular}{|c|} 
TARGET \\
POP
\end{tabular} & $\begin{array}{l}\mathrm{H} / \mathrm{H} \\
\text { seen } \\
\end{array}$ & $\begin{array}{l}\text { ROOMS } \\
\text { SPRAYED }\end{array}$ & $\begin{array}{l}\text { ROOMS } \\
\text { REFUSED }\end{array}$ & $\begin{array}{l}\text { ROOMS } \\
\text { LOCKED } \\
\end{array}$ & $\begin{array}{c}\text { ROOMS } \\
\text { SEEN }\end{array}$ & ACCEPTANCE & COVERAGE & $\begin{array}{c}\text { POP } \\
\text { PROTECTED }\end{array}$ & $\begin{array}{c}\% \text { Pop } \\
\text { Protected }\end{array}$ \\
\hline 18 Nyashanu & 5007 & 7489 & 1082 & 3151 & 382 & 655 & 4188 & 75.24 & 62.93 & 5179 & 69.15 \\
\hline 20 Betera & 5850 & 7972 & 1590 & 4395 & 455 & 744 & 5594 & 78.57 & 75.13 & 7280 & 91.32 \\
\hline 22 Masasa & 8197 & 11550 & 2240 & 5456 & 855 & 1296 & 7746 & 70.44 & 66.56 & 9628 & 83.36 \\
\hline 23 Chirozva & 6850 & 9441 & 2246 & 4121 & 1923 & 1222 & 7266 & 56.72 & 60.16 & 7864 & 83.30 \\
\hline 24 Muzokomba & 6851 & 8828 & 1992 & 4469 & 1463 & 1030 & 6962 & 64.19 & 65.23 & 7550 & 85.52 \\
\hline 25 Zangama & 6004 & 9093 & 2172 & 4380 & 1857 & 1109 & 7346 & 59.62 & 72.95 & 8140 & 89.52 \\
\hline 26 Mutepfe & 7620 & 6675 & 1928 & 5386 & 298 & 707 & 6377 & 84.46 & 70.68 & 8717 & 130.59 \\
\hline 27 Mutiusinazit & 5563 & 6774 & 1271 & 2906 & 783 & 951 & 4640 & 62.63 & 52.24 & 4970 & 73.37 \\
\hline 28 Chapanduka & 5965 & 9213 & 1760 & 3587 & 1153 & 1382 & 6122 & 58.59 & 60.13 & 7083 & 76.88 \\
\hline 29 Chabata & 7321 & 7887 & 1788 & 4358 & 782 & 1062 & 6202 & 70.27 & 59.53 & 7496 & 95.04 \\
\hline 30 Gunura & 3727 & 4114 & 1005 & 2557 & 330 & 683 & 3570 & 71.62 & 68.61 & 3456 & 84.01 \\
\hline $33 \mathrm{~B} / \mathrm{B}$ & 6136 & 8106 & 2176 & 5233 & 1496 & 1420 & 8149 & 64.22 & 85.28 & 8091 & 99.81 \\
\hline TOTAL & 75091 & 97142 & 21250 & 49999 & 11777 & 12261 & 74162 & 67.42 & 66.58 & 85454 & 87.97 \\
\hline
\end{tabular}

Table 32018 Wards IRS coverage and achievements

\begin{tabular}{|c|c|c|c|c|c|c|c|c|c|c|c|c|}
\hline \multirow[t]{2}{*}{ Ward } & \multirow[t]{2}{*}{ Targeted/h } & \multirow{2}{*}{$\begin{array}{l}\text { h targeted } \\
\text { rooms }\end{array}$} & \multirow{2}{*}{$\begin{array}{c}\text { dtargeted } \\
\text { pop }\end{array}$} & \multirow{2}{*}{$\left|\begin{array}{c}\text { Number } \\
\text { of } \mathrm{h} / \mathrm{h} \\
\text { seen }\end{array}\right|$} & \multicolumn{5}{|c|}{ Rooms } & \multirow{2}{*}{$\begin{array}{c}\% \text { of } \\
\text { rooms } \\
\text { sprayed }\end{array} \mid$} & \multicolumn{2}{|c|}{ Population } \\
\hline & & & & & Sprayed & Refused & hocked & $\begin{array}{l}\text { total } \\
\text { rooms } \\
\text { seen }\end{array}$ & $\begin{array}{c}\% \text { s } \\
\text { sprayed }\end{array}$ & & protected & $\begin{array}{c}\% \\
\text { pop } \\
\text { protected }\end{array}$ \\
\hline 18 & 1082 & 4230 & 7489 & 0 & 0 & 0 & 0 & 0 & 0 & 0 & 0 & 0 \\
\hline 20 & 1590 & 5706 & 7972 & 332 & 822 & 230 & 146 & 1198 & 63 & 14 & 1222 & 15 \\
\hline 22 & 2240 & 7901 & 11550 & 2549 & 5702 & 1963 & 924 & 8589 & 484 & 72 & 9980 & 86 \\
\hline 23 & 2246 & 7411 & 9441 & 2434 & 5295 & 980 & 554 & 6829 & 347 & 71 & 9243 & 98 \\
\hline 24 & 1992 & 7101 & 8828 & 2211 & 5122 & 1572 & 961 & 7655 & 531 & 72 & 8033 & 91 \\
\hline 25 & 2172 & 7493 & 9093 & 2338 & 4445 & 2204 & 1152 & 7801 & 738 & 59 & 7988 & 88 \\
\hline 26 & 1928 & 6505 & 6675 & 2118 & 4878 & 1312 & 806 & 6996 & 908 & 75 & 7464 & 112 \\
\hline 27 & 1271 & 4733 & 6774 & 1416 & 2884 & 1461 & 617 & 4962 & 569 & 61 & 4839 & 71 \\
\hline 28 & 1760 & 6244 & 9213 & 0 & 0 & 0 & 0 & 0 & 0 & 0 & 0 & 0 \\
\hline 29 & 1788 & 6326 & 7887 & 2258 & 4387 & 1834 & 1789 & 8010 & 961 & 69 & 6761 & 86 \\
\hline 30 & 1005 & 3641 & 4114 & 973 & 1858 & 656 & 1083 & 3597 & 350 & 51 & 2737 & 67 \\
\hline 33 & 2176 & 8312 & 8106 & 2329 & 4557 & 2416 & 1646 & 8619 & 705 & 55 & 6868 & 85 \\
\hline Totals & s 21250 & 75603 & 97142 & 18958 & 39950 & 14628 & 9678 & 64256 & 55656 & 53 & 65135 & 67 \\
\hline
\end{tabular}


Table 42019 Wards IRS coverage and achievements

\begin{tabular}{|l|l|l|l|l|l|l|}
\hline $\begin{array}{l}\text { Ward } \\
\text { Number }\end{array}$ & $\begin{array}{l}\text { Targeted } \\
\text { Rooms }\end{array}$ & $\begin{array}{l}\text { Sprayed } \\
\text { Rooms }\end{array}$ & $\begin{array}{l}\text { \% Rooms } \\
\text { Sprayed }\end{array}$ & $\begin{array}{l}\text { Targeted } \\
\text { Population }\end{array}$ & $\begin{array}{l}\text { Population } \\
\text { Protected }\end{array}$ & $\begin{array}{l}\text { \% Population } \\
\text { Protected }\end{array}$ \\
\hline 18 & 4230 & 3905 & 92.32 & 7489 & 6200 & 82.79 \\
\hline 20 & 5706 & 4771 & 83.61 & 7972 & 7491 & 93.97 \\
\hline 22 & 7901 & 6953 & 88.00 & 11550 & 11466 & 99.27 \\
\hline 23 & 7411 & 6847 & 92.39 & 10730 & 10730 & 100.00 \\
\hline 24 & 7101 & 6121 & 86.20 & 9142 & 9142 & 100.00 \\
\hline 25 & 7493 & 6253 & 83.45 & 9980 & 9980 & 100.00 \\
\hline 26 & 6505 & 4821 & 74.11 & 7345 & 7345 & 100.00 \\
\hline 27 & 4733 & 3973 & 83.94 & 6774 & 6399 & 94.46 \\
\hline 28 & 6244 & 6422 & 102.85 & 9709 & 9709 & 100.00 \\
\hline 29 & 6326 & 4199 & 66.38 & 7887 & 5854 & 74.22 \\
\hline 30 & 3641 & 2729 & 74.95 & 4114 & 4129 & 100.36 \\
\hline 33 & 8312 & 5993 & 72.10 & 9023 & 9023 & 100.00 \\
\hline
\end{tabular}

Table 5 Overall IRS performance coverage comparative analysis: 2015 to 2019

\begin{tabular}{|l|l|l|l|l|l|}
\hline Year & $\begin{array}{l}\text { Targeted } \\
\text { Rooms }\end{array}$ & $\begin{array}{l}\text { \% Sprayed } \\
\text { Rooms }\end{array}$ & $\begin{array}{l}\text { Targeted } \\
\text { population }\end{array}$ & $\begin{array}{l}\text { Population } \\
\text { Protected }\end{array}$ & $\begin{array}{l}\text { \% Population } \\
\text { Protected }\end{array}$ \\
\hline 2015 & 60608 & 90.1 & 94252 & 94252 & 100 \\
\hline 2016 & 73537 & 66.3 & 97214 & 82632 & 85 \\
\hline 2017 & 75091 & 66.5 & 97140 & 85454 & 87.97 \\
\hline 2018 & 75603 & 53 & 97142 & 65135 & 67 \\
\hline 2019 & 75603 & 83.31 & 101715 & 97468 & 95.82 \\
\hline
\end{tabular}

Table 6 Pre and Post-COVID-19 outbreak confirmed malaria cases 


\begin{tabular}{|c|l|l|l|}
\hline Period & Year & Malaria confirmed cases(tested positive) & Malaria deaths \\
\hline Pre-COVID-19 outbreak & 2015 & 974 & 18 \\
\cline { 2 - 4 } & 2016 & 1015 & 8 \\
\cline { 2 - 5 } & 2017 & 2286 & 12 \\
\cline { 2 - 5 } & 2018 & 701 & 1 \\
\cline { 2 - 5 } & 2019 & 1376 & 13 \\
\hline Post-COVID-19 outbreak & 2020 & 2981 & 18 \\
\hline Grand Total & 9333 & 70 \\
\hline
\end{tabular}

\section{Figures}

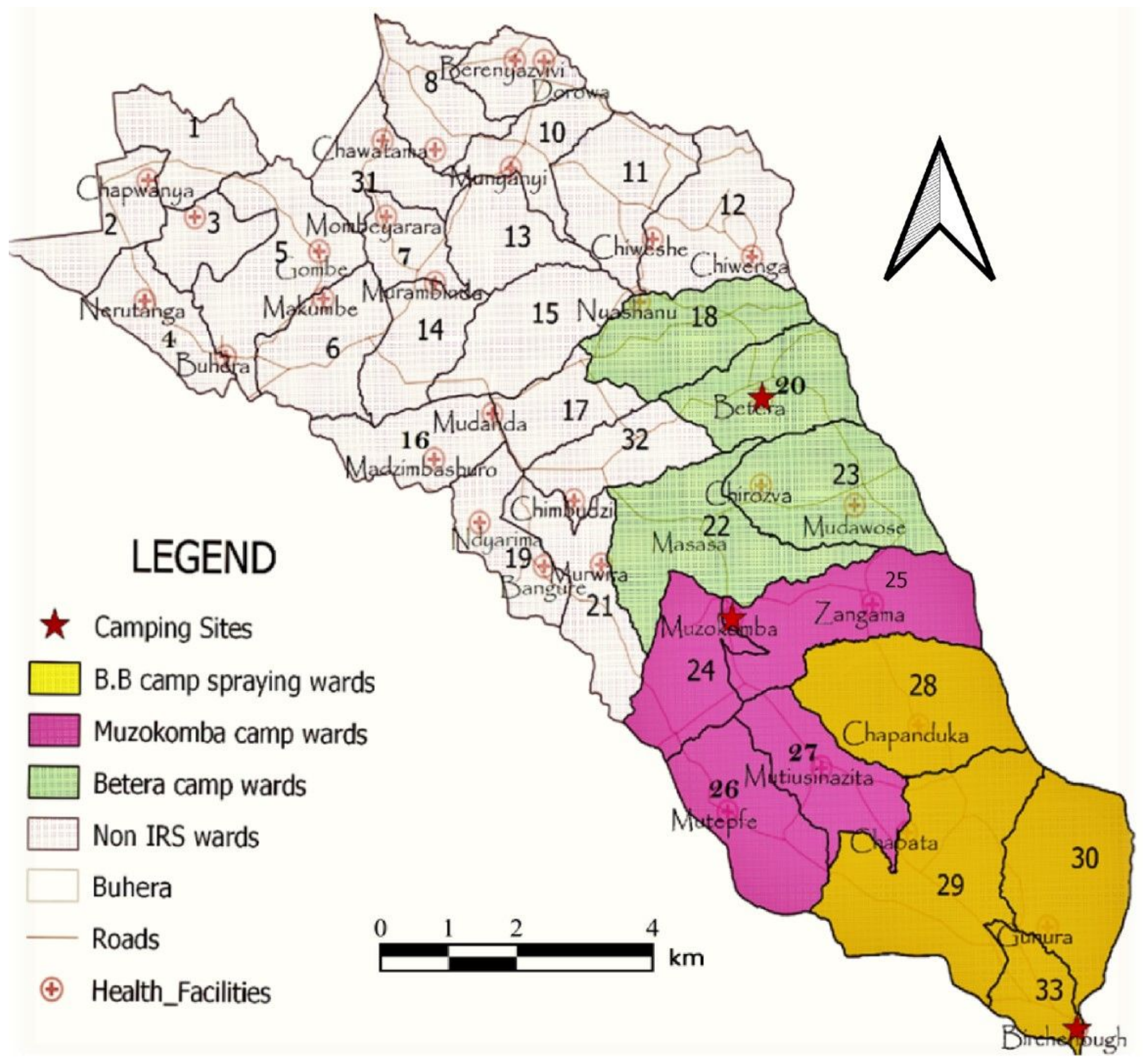




\section{Figure 1}

Buhera map showing camp wards. Note: The designations employed and the presentation of the material on this map do not imply the expression of any opinion whatsoever on the part of Research Square concerning the legal status of any country, territory, city or area or of its authorities, or concerning the delimitation of its frontiers or boundaries. This map has been provided by the authors.

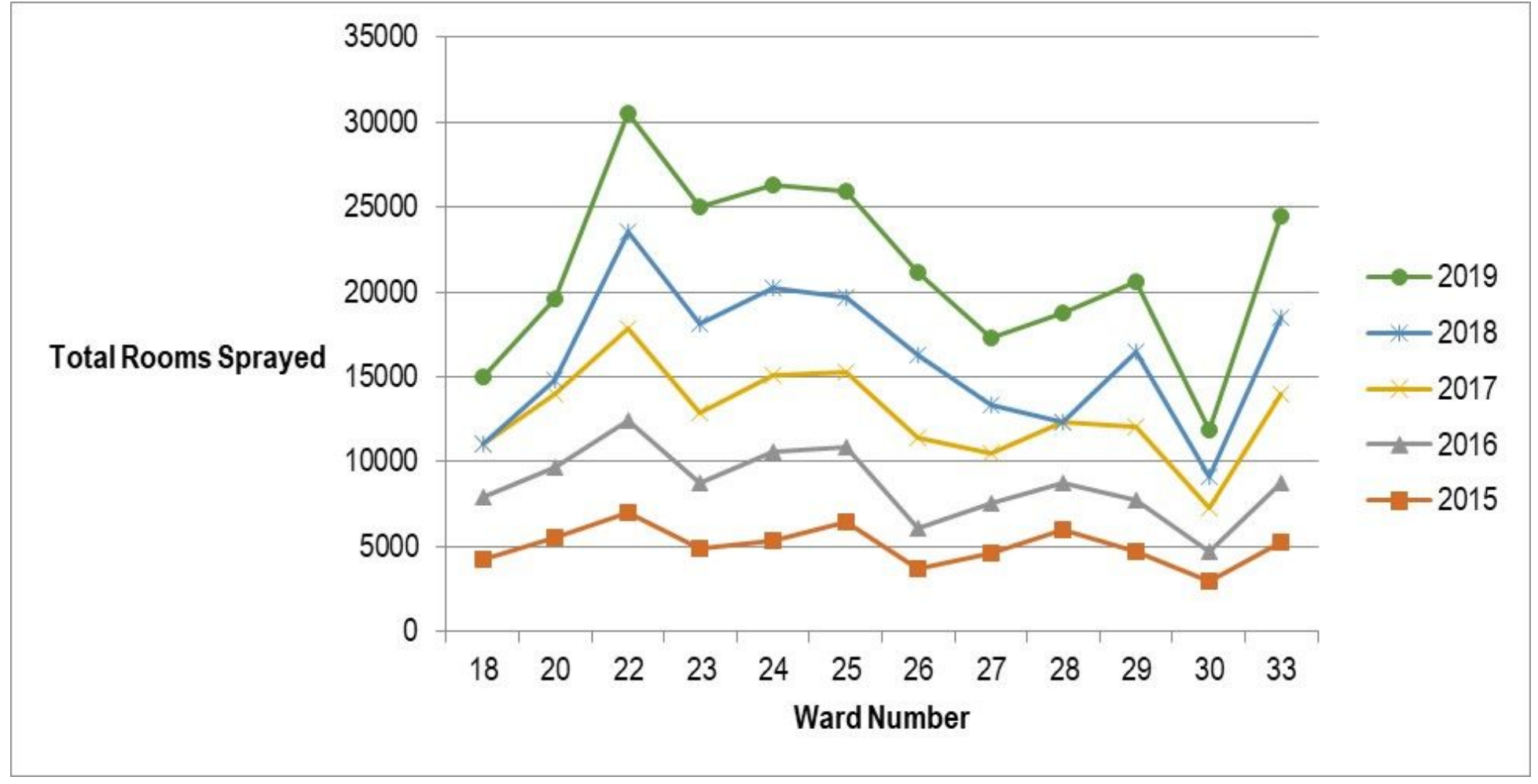

Figure 2

Sprayed Rooms from 2015-2019 


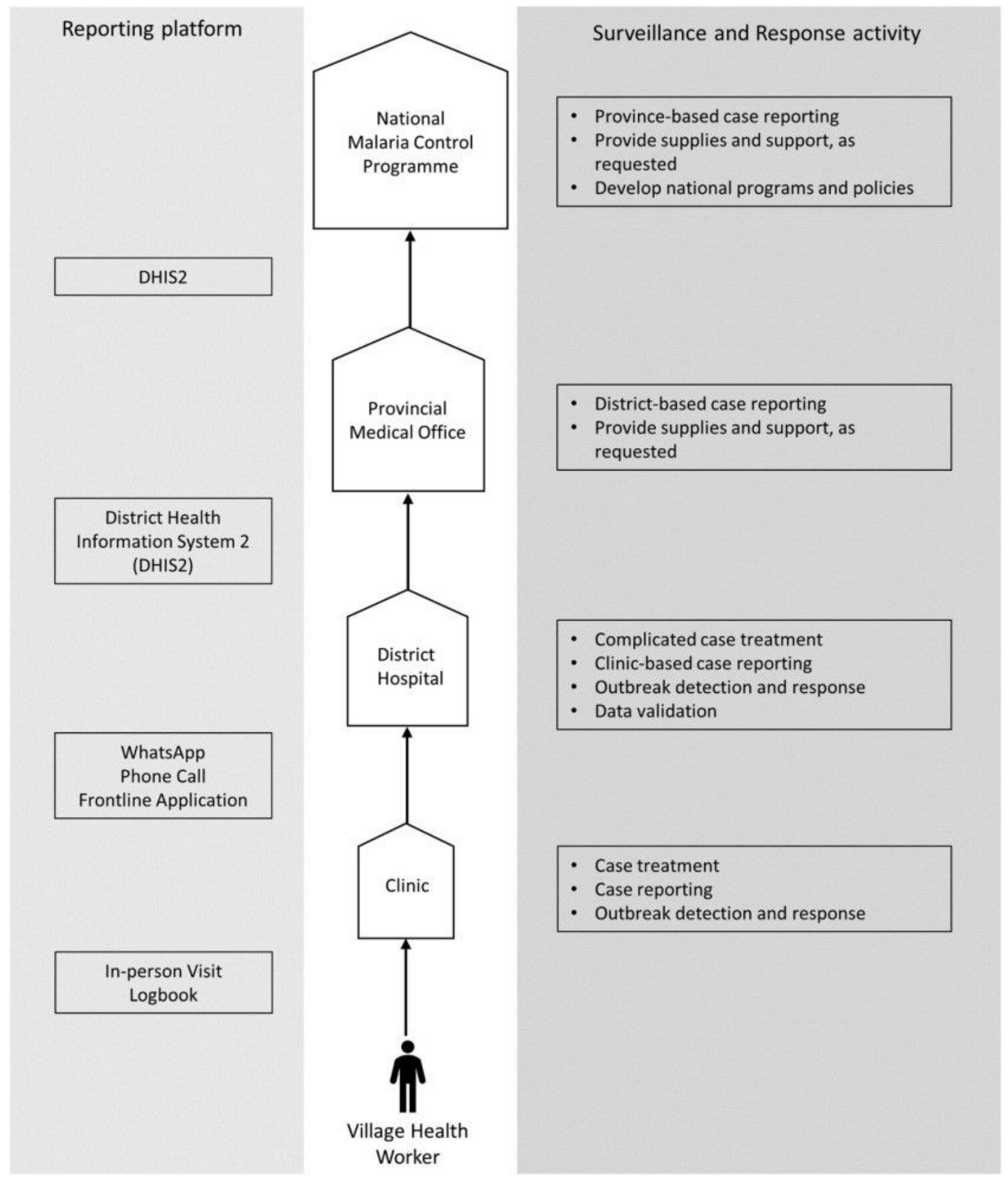

\section{Figure 3}

Zimbabwe's malaria outbreak detection and response surveillance system reporting structure[2] 


\section{BUHERA MAP SHOWING MALARIA DISTRIBUTION}

Legend

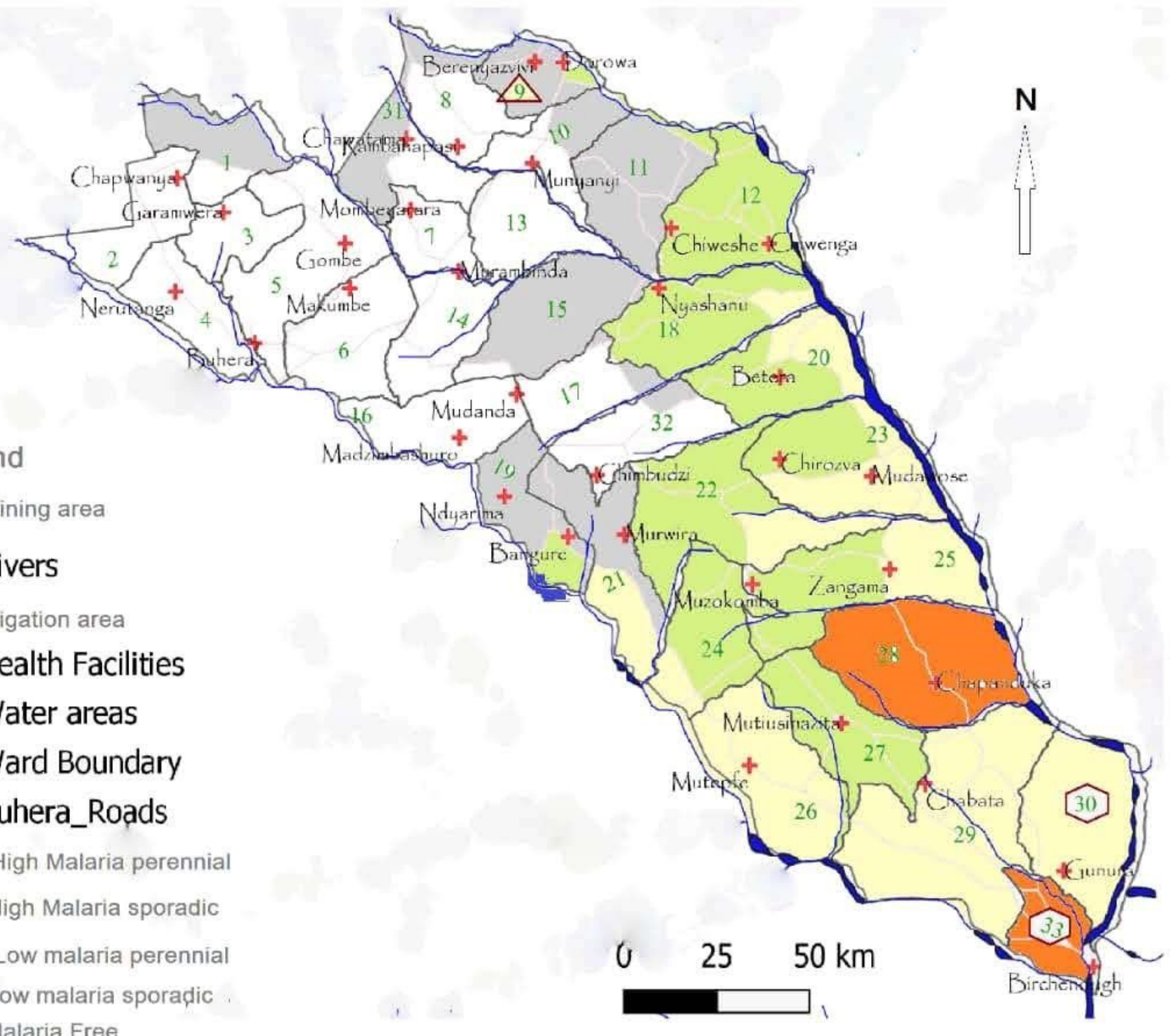

Malaria Free

Figure 4

Malaria hotspots areas and distribution. Note: The designations employed and the presentation of the material on this map do not imply the expression of any opinion whatsoever on the part of Research Square concerning the legal status of any country, territory, city or area or of its authorities, or concerning the delimitation of its frontiers or boundaries. This map has been provided by the authors. 